\title{
Study of Photovoltaics (PV) Performance Degradation Analysis in Oman
}

\author{
Mohamed Shaik Honnurvali ${ }^{1}$, Naren Gupta ${ }^{2}$, KengGoh $^{2}$, Tariq $\mathrm{Umar}^{3}$, Needa Nazeema ${ }^{4}$ \\ Asharqiyah University ${ }^{1,3}$, Oman \\ Edinburgh Napier University ${ }^{2}, U K$ \\ ITS Engineering Institute ${ }^{4}$, India
}

\begin{abstract}
The demand for electricity usage is increasing all around the globe. As an alternative and clean source to produce electricity there has been an emphasis on the usage of renewable energies. Sultanate of Oman has also taken an initiative by 2030 that at least $15 \%$ of the total energy mix should be generated through renewables. Considering the investments made in future it is also vital to estimate the Performance and reliability of $P V$ modules under local climatic conditions. The surveyed data analysis of five sites under local climatic conditions has shown that the visual degradations such as encapsulate discolouration and delamination are main causes in old age group modules for higher degradation rates. Infrared (IR)-image analysis has shown that $P V$ modules with 'hot cells' have higher degradation rates than the modules without 'hot cells'. The interconnect test results have indicated that series resistance increases with the increase in the severity of interconnect breakages (SIB) thus increasing the output power degradation rates. Electrical parameter data analysis has shown that all the module average power degradation rate is $2.05 \% / y e a r$ which is much higher than European counties. CdTe PV technology has shown fewer degradation rates which is less than $1 \% / y e a r$ and seems to be the best choice in the local climatic conditions. The average degradation rate with regard to $P V$ module size is higher for small size and lower for a larger size. In the contrary with regard to $P V$ system size, larger size has observed with fewer degradation rates. The roof-mounted installations have also observed with higher degradation rates than the ground-based installations.
\end{abstract}

\section{Introduction}

Sultanate of Oman having a total area of 309,500 square kilometres of which $82 \%$ is desert, $15 \%$ is cliffs, leaving only $3 \%$ of the land suitable for living conditions. Despite this, Sultanate of Oman plays a key role in Gulf Cooperation Council (GCC) countries and has shown rapid modernization through the development of excellent world-class projects thereby enhancing the living standards and a key player in globalization [1].

The total population of Oman is around 46 million of which $55 \%$ are nationals (Omanis) and remaining $45 \%$ expats [2]. The skilled labour deficit of local nationals has attracted many other countries skilled labours to build the infrastructure capabilities of the country in engineering, medical sector, health \& safety, construction sector etc. As a result, the energy electricity demand has seen an increase of about $9 \%$ per year. It has been estimated that by 2022 the peak electricity demand will rise to around $9600 \mathrm{MW}$ from 5600 MW (in 2015) [3]. The main sources of energy production in Oman like other GCC countries is done by non-renewable energy sources such as oil and gas etc. Energy consumption is predicted to raise up to 47 TWh by 2021 from $25 \mathrm{TWh}$ (in 2015) which is again 9\% annual increase. About $97.5 \%$ of this energy consumption is fueled by natural gas and remaining $2.5 \%$ comes through diesel. Although Oman is rich in oil and gas reserves it is predicted that will be a shortage of demand and supply of around 210 Bcf/year [4]. This shortage of natural gas is not only restricted to Oman but also other GCC countries. Therefore, it is incredibly challenging to increase the gas production levels as per the required demand. In a recent study done on the $\mathrm{CO}_{2}$ emissions in Oman during a period of last forty-two years (1972-2013) has revealed that the total $\mathrm{CO}_{2}$ emitted both by natural gas and liquid fossil fuels (crude oil, diesel, kerosene etc.) is around 54000 Gigagram [5]. It is also stated that $\mathrm{CO}_{2}$ emitted due to natural gas has a much higher share $(42000 \mathrm{Gg})$ in the total $\mathrm{CO}_{2}$ emission share. If the utilization of the natural gas gets continuously used in the production of electricity to meet the future high electricity demand, then perhaps Oman have to import natural gas rather than exporting natural gas.

Therefore, in order to avail a solution for the above-mentioned challenges the government of Oman has taken an initiative to exploit other sources of energy such as renewable energies (solar, Wind and geothermal etc.). Hussein A. Kazem [6] study has stated that solar and wind energy seems to be the prime choice of energy investments according to the local climatic conditions. Similarly, an exploratory 
study on renewable energy resources in Oman conducted by Umar and Wamuziri [7] measured the maximum wind potential in Oman at Thumrait area, while the maximum solar potential was found at Marmul area. The studies conducted by Umar [8,9] observed that apart from solar and wind, geothermal and bio mass are some forms of the renewable energy which can be adopted in Oman. Umar and Egbu [10] while discussing the global commitment towards sustainable energy noted that Oman still needs to submit their intended nationally determined contributions to UN as part of the United Nation sustainable development goals set for achievement by 2030. Umar [11] in his research on the solar rooftop energy particularly focus on the different incentives provided by the Indian government to promote the rooftop solar energy in different states. He stress that such incentive would be helpful to attract public towards adaptation of solar energy. The PAWE (public authority for water and electricity) of Oman has set a plan to achieve $15 \%(3000 \mathrm{MW})$ of the total energy mix (2000MW) through renewable energy resources by 2030. MEDC (Muscat Electricity Distribution Company) is the first and one of the MIS (Member interconnected system) has recently launched (in 2017) the solar PV system integration with the main electricity grid by which now the consumers can sell their excess electricity generated through PV systems [12]. So far, the installation size of PV systems stands around 9200KW of which about $25 \%$ was just installed in the last two years. Mainly, the crucial component of a PV system is the solar panel, which constitutes to be more than half price of the overall PV system cost. Therefore, it is important for the stakeholders, investors and researchers to understand the long-term performance of the PV modules in the Oman climatic conditions because the energy yield would decide the return on investments (ROI) and also an average lifetime of PV modules. A recent study on the feasibility of PV systems in Oman has shown grid-connected PV system is more promising and possible [13].

Usually, the performance and efficiency of PV systems are largely dependent on climatic factors such as irradiance, tilt angle, dust, temperature etc. The studies $[14,15]$ has shown that PV modules in hot and dry climatic conditions undergo a significant degradation in PV output power. Sultanate of Oman experiences hot and dry climate in the interior regions, hot and humid in summer in the coastal area, and moderate in winter. Therefore, it is highly important to understand the effect of local climatic conditions on PV systems so as to enable installers and investors to estimate the reliability of PV systems for a longer lifetime. As a result, a field visit was conducted on five different sites with different PV technologies installed in different climatic conditions of Oman.

\section{Field Survey details}

\subsection{Site and PV technology description}

The sites considered (A-E) as shown in figure. 1 in this survey are standalone projects serving different purposes such as a cooling system for buildings, street lighting and public toilets. The survey has been conducted with the help of local company installer whose name and PV manufacturer are kept anonymous in order to preserve its identity. The physical and technical details of the observed PV modules at different sites are presented in table 1 . The PV panel with monocrystalline silicon technology is observed in both hot \& dry and hot $\&$ humid climate and the age of the modules is five years (old modules). The PV module with thin film technology (CdTe) which is seen in the recent installation is two years old. The rated power per module is seen in the range of $80 \mathrm{~W}_{\mathrm{p}}$ to $200 \mathrm{~W}_{\mathrm{p}}$. For further analysis, they are divided into two categories, modules having rating power $>120 \mathrm{~W}_{\mathrm{p}}$ and $<120 \mathrm{~W}_{\mathrm{p}}$. The $\mathrm{PV}$ degradation is also affected by various nonlinearities as shown by Jordan et al. [16]. One of it is light-induced Degradation (LID) which refers to rapid initial degradation seen in mono and multi-crystalline silicon modules when exposed to irradiance (sunlight). The LID varies from one manufacturer to another and, a $2 \%$ of LID is recommended by the PVSyst software [17] which is considered in the analysis. Sopori et al. [18] work show that $40 \%$ of the total output power degradation comes from the open-circuit voltage $\left(\mathrm{V}_{\mathrm{oc}}\right)$ and another $40 \%$ by short-circuit current $\left(\mathrm{I}_{\mathrm{sc}}\right)$ and the remaining $20 \%$ by fill-factor (FF). Similarly, the analysis carried out in this paper, $2 \%$ LID has been divided into $0.8 \%$ for $\left(V_{\mathrm{oc}}\right), 0.8 \%$ for $\left(\mathrm{I}_{\mathrm{sc}}\right)$ and $0.4 \%$ for the FF.

Table 1. Description of modules at Five sites (A-E)

\begin{tabular}{|c|c|l|l|c|}
\hline $\begin{array}{l}\text { PV } \\
\text { Technology }\end{array}$ & $\begin{array}{c}\text { Hot \& } \\
\text { Dry }\end{array}$ & $\begin{array}{c}\text { Hot \& } \\
\text { Humid }\end{array}$ & $\begin{array}{c}\text { Age of } \\
\text { modules } \\
\text { (Yr) }\end{array}$ & $\begin{array}{c}\text { Rated } \\
\text { Power }\end{array}$ \\
\hline Mono-C-Si & $25(\mathrm{E})$ & $10(\mathrm{D})$ & 5 & $<120 \mathrm{~W}_{\mathrm{p}}$ \\
\hline Multi-C-Si & $15(\mathrm{E})$ & $5(\mathrm{C})$ & 3 & $>120 \mathrm{~W}_{\mathrm{p}}$ \\
\hline Thin a-si & $15(\mathrm{~A})$ & $10(\mathrm{~B})$ & 4 & $<120 \mathrm{~W}_{\mathrm{p}}$ \\
\hline CdTe & $10(\mathrm{~A})$ & $10(\mathrm{C})$ & 2 & $>120 \mathrm{~W}_{\mathrm{p}}$ \\
\hline
\end{tabular}




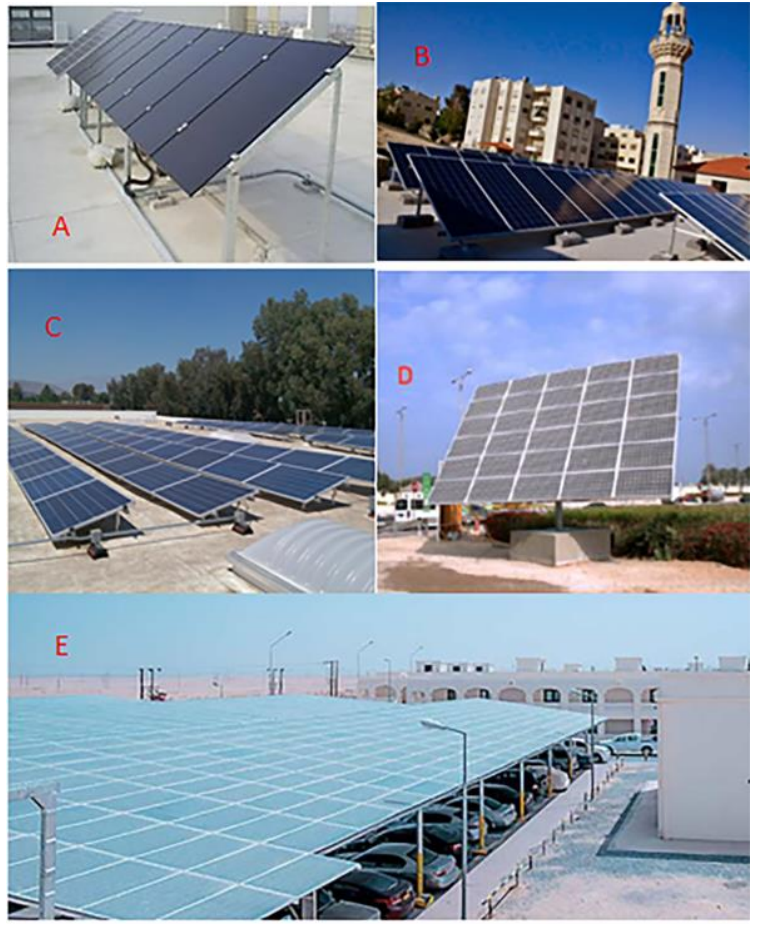

Figure 1. Surveyed Five sites (A-E)

\subsection{Applied Methodology}

The dust observed at the sites was first made clear by flowing water from the top and cleaning off before any measurements were made. The measurement of I$\mathrm{V}$ curves of different $\mathrm{PV}$ modules requires the entire system to be disconnected from load prior to taking the measurement. visual inspection using a checklist, IR imaging to observe the module temperature and hotspots, interconnect test using cell line checker to identify the interconnect breakages, were performed in daylight.

2.2.1. Visual Inspection. Visual degradation observations such as encapsulation discolouration and delamination are recorded in the checklist [19]. Furthermore, clear digital images were taken for certain damaged modules to be able to inspect it later and at the point of interested regions in the PV modules, to be able to inspect them later

2.2.2. Infra-red (IR) Images. IR images play a vital role to identify hotspots formation in the PV modules. Two sets of IR images were taken during survey first, when the system connected with load (i.e. system connected to MPPT) second, by short-circuiting the PV modules individually. All the images were taken when the irradiance is above $600 \mathrm{~W} / \mathrm{m}^{2}$, to identify hotspots properly.
2.2.3. Interconnects Breakage Tests. PV module internally consists of PV cells; The PV cells are series connected each other with interconnects so as to allow the electron flow generated in the PV modules. Tamizhmani.G et al. [20] have reported, in hot and dry climatic conditions failure of interconnects was one of the most regular failure modes. Togami cell line checker was used to determine the interconnect failures. It consists of two units a transmitter and a receiver. The transmitter is connected to PV module output terminals and the receiver is placed on the interconnect lines surface. The health of the interconnect lines is observed on the LED flash scale (0 to 10) where 0 indicates a complete failure of interconnect lines and 10 indicates non-damaged interconnect lines.

2.2.4. current-voltage (I-V) curves. The electrical parameters performance of PV modules such as opencircuit voltage $\left(V_{o c}\right)$, short-circuit current $\left(I_{s c}\right)$, maximum output power $\left(\mathrm{P}_{\max }\right)$ and Fill Factor $(\mathrm{FF})$ are diagnosed by measuring $\mathrm{I}-\mathrm{V}$ curves. A portable MECO solar I-V curve tracer is used to record I-V curves of different PV modules simultaneously. At least three sets of I-V curves are recorded for each PV module at an interval of 2 minutes. Additional accessories such as global irradiance, the plane of Array (POA) and module temperature are also connected during measurements. STC translation of the surveyed data is done where necessary, in order to obtain the degradation rates of electrical parameters according to STC conditions (i.e. $1000 \mathrm{~W} / \mathrm{m}^{2}$ and $25^{\circ} \mathrm{C}$ module temperature). The ambient temperature and relative humidity are also measured while recording I-V curves.

\section{Observations and results}

\subsection{Visual degradation}

Variety of components in PV modules degrade when exposed to the harsh outdoor environments such as UV rays of solar radiation, high temperatures and humidity levels etc. The major visual degradations observed on site are due to encapsulation discolouration and front-side delamination. Discoloration of encapsulant contributes to the reduction of short-circuit current $\left(\mathrm{I}_{\mathrm{sc}}\right)$ which leads to a reduction in the maximum power output $\left(\mathrm{P}_{\max }\right)$. usually, Ethyl Vinyl Acetate (EVA) is the most regular encapsulant found in the surveyed PV modules because of its low cost and favourable properties. However, proper additivities need to be mixed to avoid pre-timely discolouration as it is sensitive to photo-thermal degradation. Table II. Shows the discolouration seen in all modules and the percentage represents the modules affected due to discolouration. One can observe in young module group (0-2 yrs. Old) under hot and dry climate PV 
modules have observed with a high percentage of encapsulate discolouration. While in the mid-age group modules (i.e. 2-4 yrs. Old) under hot and humid climate PV modules has seen with a high percentage of encapsulant discolouration. Overall, in all climates, the old age group modules have observed with significant encapsulate discolouration since the modules have exposed to UV rays for a long time. However, at one site some PV modules whose age of operation is more than 5+ years but did not show any discolouration. This leads us to suspect that the encapsulate present in these modules seem to have manufactured with high-grade materials (not EVA) or the cerium content of the glass might be very high which prevents UV rays to enter into the module thereby avoiding encapsulate discolouration.

Table 2. Percentage Of All Modules Effected By Encapsulate Discolouration

\begin{tabular}{|c|c|c|c|}
\hline Climatic Zone & $\mathbf{0 - 2}$ yrs. & $\begin{array}{c}\mathbf{2 - 4} \text { yrs. } \\
\text { old }\end{array}$ & $\begin{array}{c}\text { 5-5+ yrs. } \\
\text { old }\end{array}$ \\
\hline Hot \& Dry & $40 \%(10)$ & $30 \%(30)$ & $80 \%(25)$ \\
\hline Hot \& Humid & $2 \%(10)$ & $80 \%(15)$ & $80 \%(10)$ \\
\hline $\begin{array}{c}\text { All climates } \\
\text { comparitively) }\end{array}$ & $21 \%(20)$ & $47 \%(45)$ & $80 \%(35)$ \\
\hline
\end{tabular}

Due to encapsulant discolouration another visual effect, front-side delamination is also observed in the surveyed sites. It mainly occurs when there is a loss of adhesion between the glass and encapsulant or between the PV cell and encapsulant. Due to which reflection losses increases in the affected area thereby decreasing the current production. Table III. Provides the statistics of the percentage of the PV modules affected due to delamination. A high percentage of delamination is seen in old age modules (i.e. 5-5+ yrs.) in hot and humid climatic conditions. The reason for this could be due to non-escape of vapours that arise during encapsulation discolouration which gets trapped under the glass and thus forming bubbles around that area causing delamination.

Table 3. Percentage of All Modules affected by front side delamination

\begin{tabular}{|c|c|c|c|}
\hline Climatic Zone & $\mathbf{0 - 2}$ yrs. & $\begin{array}{c}\mathbf{2 - 4} \text { yrs. } \\
\text { old }\end{array}$ & $\begin{array}{c}5-5+\text { yrs. } \\
\text { old }\end{array}$ \\
\hline Hot \& Dry & $4 \%(10)$ & $50 \%(30)$ & $65 \%(25)$ \\
\hline Hot \& Humid & $1 \%(10)$ & $52 \%(15)$ & $90 \%(10)$ \\
\hline $\begin{array}{c}\text { All climates } \\
\text { comparitively) }\end{array}$ & $2.5 \%(20)$ & $51 \%(45)$ & $72 \%(35)$ \\
\hline
\end{tabular}

The delamination observed in middle age group modules is mainly because of snail tracks where small bubbles are formed around it causing delamination. Although about half percentage of cells are observed with delamination in middle age group modules the severity of it was very less. Overall the discolouration of encapsulation seems to be the major cause for delamination as the percentage of cells observed with discolouration is also found to be delaminated in both the climatic zones.

\subsection{Infra-red imaging}

PV modules suffer from various defects which are not visual. They can cause a rise in the temperature of the PV cells thereby affecting the performance of the whole PV modules. Such regions in the PV modules need to be identified easily by taking Infrared-images. FLIR E40 thermal camera was used to collect infrared image samples of the PV modules. Two sets of images are recorded during the survey first when PV modules are connected with MPPT load and second in short circuit conditions. The Infra-red images were taken only when the irradiance level was at least more than $600 \mathrm{~W} / \mathrm{m}^{2}$. The hotspots observed during shortcircuit conditions can be treated as worst case scenario since the complete input solar energy is released as heat in short-circuit condition, while in MPPT load conditions they are less severe and representing actual operating conditions. Figure 2 shows IR images taken under a) when connected to MPPT load and b) in short circuit conditions. The vertical bar indicates the temperature range of objects seen in the IR image. The top left side temperature on the screen indicates the temperature of the pointer in the centre of IR image. The highlighted blue rectangles in short-circuit IR image (b) are the areas where the hot-spot formation is observed and the temperature levels are much higher than the image taken under MPPT load as evident from the figure. 2(b). Using Matlab image analysis tool, the point of interest (areas where hotspots are observed) in IR image samples are converted into their respective histograms which enable us to record the maximum cell temperature at that region (we call these regions as hot cells in our analysis). PV module temperature under MPPT load is recorded without any correction applied. The lowest temperature under MPPT load is $30^{\circ} \mathrm{C}$ (in hot and humid climate) on the other hand the highest recorded is $72^{\circ} \mathrm{C}$ (in hot and dry climate). The maximum cell temperature recorded in the survey under MPPT load conditions is $91.1^{\circ} \mathrm{C}$. Similarly, under short circuit conditions, the $\mathrm{PV}$ module temperature was in the range of $45^{\circ} \mathrm{C}$ to $82^{\circ} \mathrm{C}$, and the highest cell temperature observed in short-circuit conditions is $120^{\circ} \mathrm{C}$. therefore, the cell temperatures were higher in short-circuit condition when compared with the MPPT load conditions. Since the acquired data is taken at different times on different days it is necessary to translate these obtained values to reference conditions so as to deduce definitive conclusions. 


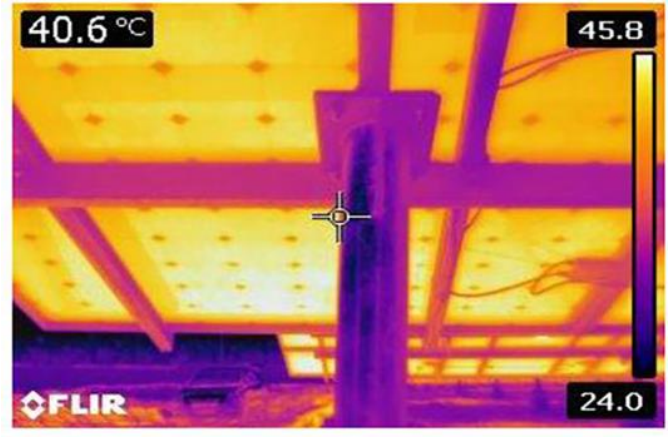

(a)

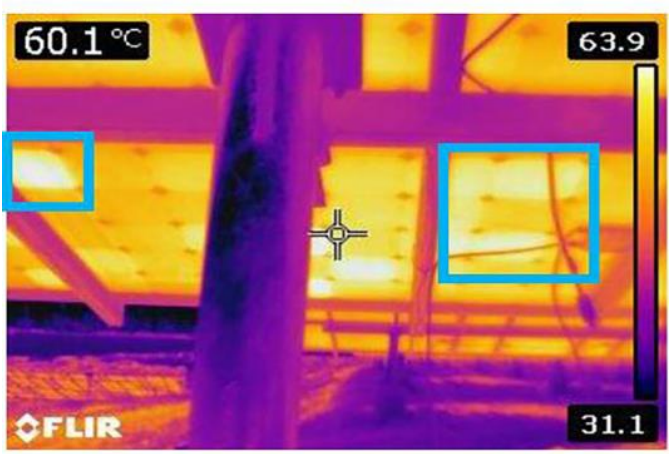

(b)

Figure 2. Sample IR Images of PV modules in the survey a) Under MPPT load condition b) under short-circuit condition

The temperatures of the acquired values during the survey are converted to standard conditions [21, 22] using the relation shown in equation (1).

$$
\begin{aligned}
& T_{\text {normalised }} \\
& =40+\frac{\left(T_{\text {measured }}-T_{\text {ambient }}\right) \times 1000}{\text { Irradiance }}
\end{aligned}
$$

Where, $T_{\text {normalised }}$ is normalised temperature, $T_{\text {measured }}$ is module temperature (from IR image) and $T_{\text {ambient }}$ is ambient temperature at site. Further module $\Delta T$ is calculated by the equation (2), where

$$
\text { module } \Delta T=T_{\text {maxcell,norm }}-T_{\text {module,norm }}
$$

$T_{\text {maxcell,norm }}$ is the normalised maximum cell temperature of the module and $T_{\text {modulenorm }}$ is the normalised modal temperature of the module. The module $\Delta T$ gives the mismatch between the different cell temperatures of the PV module. The PV modules with hotspots areas are called as 'hot cells' because the module $\Delta T$ in hotspot cells observed is higher at least in $10^{\circ} \mathrm{C}$ than the surrounding areas of the PV modules. Further, effect of these 'hot cells' on total output power degradation is evaluated in two different climatic conditions as shown in Table 4.
Table 4. Impact of hot cells on PV output power degradation rates

\begin{tabular}{|c|c|c|c|c|}
\hline \multirow{2}{*}{$\begin{array}{c}\text { Parameter } \\
\text { (in average) }\end{array}$} & \multicolumn{2}{|c|}{ Hot \& Dry } & \multicolumn{2}{c|}{ Hot \& Humid } \\
\cline { 2 - 5 } & $\begin{array}{c}\text { With } \\
\text { out } \\
\text { hot } \\
\text { cells }\end{array}$ & $\begin{array}{c}\text { With } \\
\text { hot } \\
\text { cells }\end{array}$ & $\begin{array}{c}\text { Without } \\
\text { hot cells }\end{array}$ & $\begin{array}{c}\text { With } \\
\text { hot cells }\end{array}$ \\
\hline $\begin{array}{c}\text { Power } \\
\text { degradation } \\
\text { rate }(\% / y e a r)\end{array}$ & 1.59 & 2.21 & 1.52 & 1.82 \\
\hline $\begin{array}{c}\text { Normalized } \\
\text { module } \Delta \mathrm{T} \\
\left({ }^{\circ} \mathrm{C}\right)\end{array}$ & 8.6 & 34.2 & 7.9 & 21.2 \\
\hline $\begin{array}{c}\text { Normalized } \\
\text { maximum cell } \\
\text { temperature } \\
\left({ }^{\circ} \mathrm{C}\right)\end{array}$ & 74.8 & 94.2 & 65.4 & 78.8 \\
\hline $\begin{array}{c}\text { No. of } \\
\text { Samples }\end{array}$ & 5 & 10 & 8 & 12 \\
\hline
\end{tabular}

However, the trend is significant, one can observe from Table 4. that the PV modules with 'hot cells' in both the climatic zones are degrading faster than the regions without hot cells. Comparing with regard to climatic conditions, the degradation rate is higher in hot $\&$ dry than the hot and humid climate conditions. One can also notice from table 4 . That there is a good positive correlation between the average power degradation with the normalized module $\Delta \mathrm{T}$ (i.e. increase in $\Delta \mathrm{T}$ causes increase in the power degradation rates).

\subsection{Interconnect Breakage Tests}

Interconnects form a crucial part of PV modules. Interconnects conduct the generated electricity from PV cells to the external load. Normally there are around 3 to 4 interconnects around each cell and any failure in interconnects will redirect the electricity flow into other interconnects which causes loading effect. Due to the loading effect of interconnects the series resistance of the PV modules increases which further causes degradation in fill factor thus reducing the output power of the PV modules. A togami cell line checker was used to test the quality of interconnects in the PV modules. The interconnect breakages found in this survey are classified into two types 1 . Line breakage 2. Point breakage. A line breakage in the PV module can be defined as breakage along the continuous line of the busbar. On the other hand, if the breakage occurs at specific points along the busbar, it is termed as point breakage. To understand the contribution of these breakages in the increase of series resistance of PV module a formula has been derived which is termed as 'severity of

$$
S I B=\frac{\text { No. of cells effected }}{\text { Total No. of cells in module }}
$$


interconnects' (SIB) as shown in equation (2). It is given as the ratio of number of cells affected with the interconnect breakage by the total number of cells in the PV module.

Table 5. Percentage of All Modules effected by Interconnect breakages

\begin{tabular}{|c|c|c|c|}
\hline Climatic Zone & $\mathbf{0 - 2}$ yrs. & $\begin{array}{c}\text { 2-4 yrs. } \\
\text { old }\end{array}$ & $\begin{array}{c}5-5+\text { yrs. } \\
\text { old }\end{array}$ \\
\hline Hot \& Dry & $4 \%(10)$ & $10 \%(30)$ & $57 \%(25)$ \\
\hline Hot \& Humid & $4 \%(10)$ & $4 \%(15)$ & $40 \%(10)$ \\
\hline $\begin{array}{c}\text { All climates } \\
\text { comparitively) }\end{array}$ & $4 \%(20)$ & $8 \%(45)$ & $42 \%(35)$ \\
\hline
\end{tabular}

The table V shows the statistics of the interconnect breakages observed in different climatic conditions of different age groups. The percentage of the cells affected by interconnect breakages is about $27 \%$ (65) in hot and dry climatic conditions and $14 \%$ (35) in hot and humid climatic conditions. The cause for high interconnect failures in hot and dry climate is likely due to thermal cycling because of change in temperatures in day and night. Similarly, one can notice that in the old age group of hot and humid climate has seen with higher interconnect failures. The reason could be due to corrosion of busbar which is found widely in this age group. Furthermore, An average of SIB (Severity of interconnect failures) is calculated for all modules as shown in figure $3 \mathrm{a}$. one can also notice that as the SIB increases series resistance also increases.

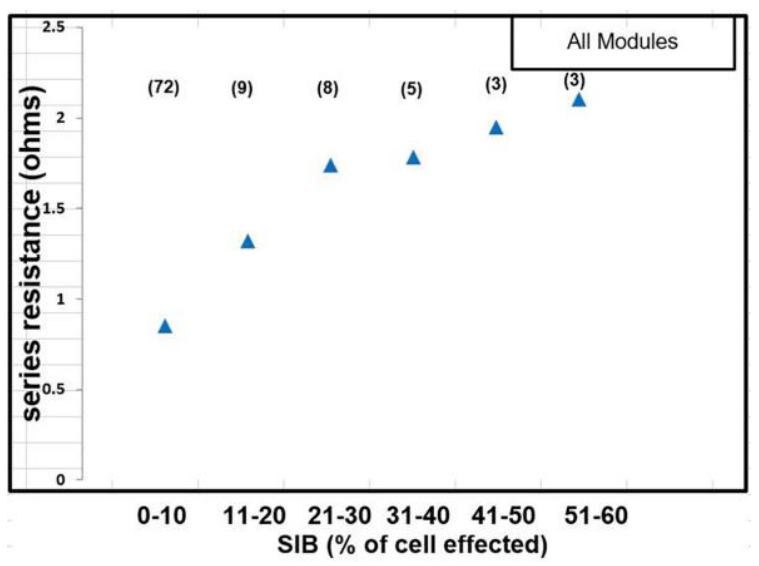

(a)

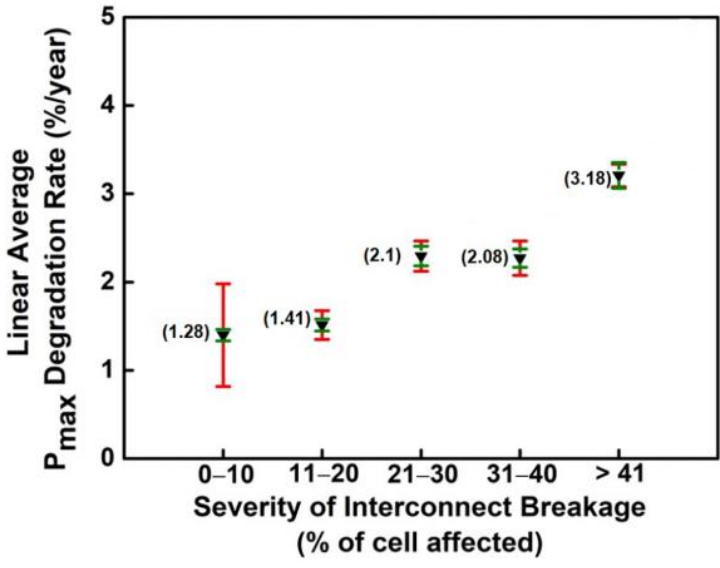

(b)

Figure 3. Correlation graphs

a) average value of series resistance with SIB

b) $\mathrm{p}_{\max }$ degradation rates (\%/year) with SIB

The numbers at the top of figure 3 a show the number of modules whose series resistance is present at particular range as shown in figure $3 \mathrm{a}$. The correlation of $\mathrm{P}_{\max }$ degradation rate (\%/year) with SIB is shown in figure $3 \mathrm{~b}$. one can observe that as the SIB increases the power degradation rates are also increased. The red line indicates the confidence interval. This shows that the failure of interconnects causes an increase in series resistance as a result output power degradation rates are also increased.

\subsection{Electrical Degradation Analysis}

Currently, there is strong push all over the world to generate the electricity through renewable energy resources and also huge investments are being made both in developed and developing countries. Therefore, to understand the reliability and performance of PV systems on field conditions it is vital to estimate the maximum output power on site. Further, the obtained values are translated into STC conditions using IEC-STC procedures 1a. as explained in our previous work [23] to calculate the power degradation rates. This translation will allow us to compare the PV module's current day performance with its original performance (during the first installation of the PV modules). The percentage degradation rates of PV electrical parameters such as maximum output power $\left(\mathrm{P}_{\max }\right)$, short-circuit current $\left(\mathrm{I}_{\mathrm{sc}}\right)$, open-circuit voltage $\left(\mathrm{V}_{\mathrm{oc}}\right)$ and fill factor $(\mathrm{FF})$ are estimated. Series resistance and the shunt resistance are also calculated from the I-V curves. 


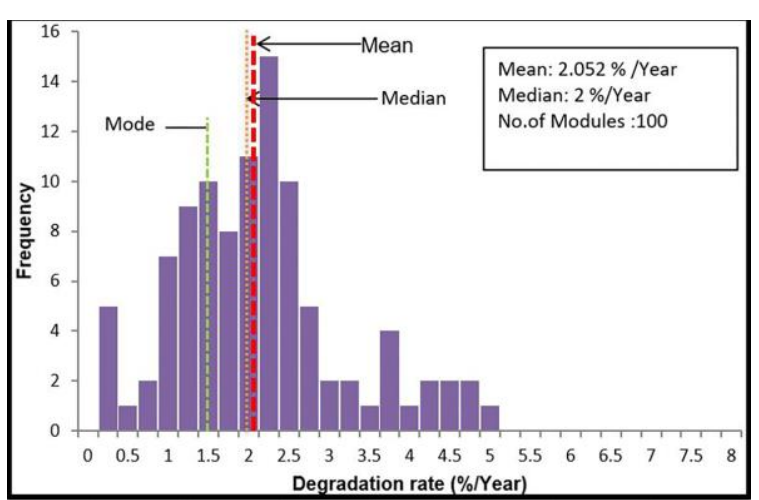

(a)

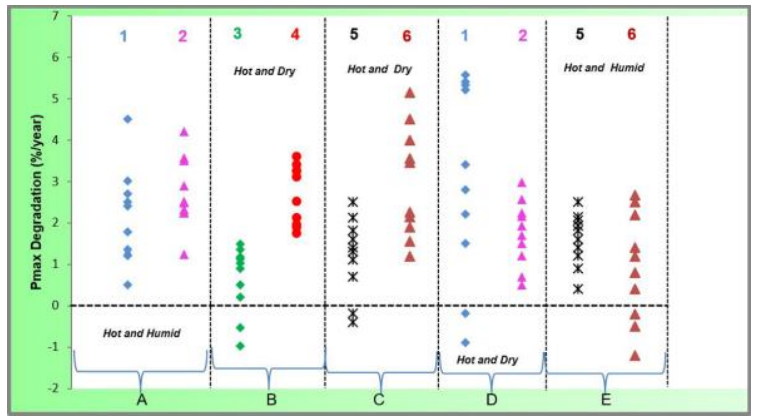

(b)

Figure 4. $\mathrm{P}_{\max }$ degradation rates

a) All modules histogram

b) Site-wise, Manufacturer and climate wise. 1-6 number represents different manufacturers

Overall, about 110 different PV technology modules in the five sites have been inspected in our case study. However, due to low irradiance about 10 $\mathrm{I}-\mathrm{V}$ curves are not considered. The figure 4(a). shows the histogram of the considered 100 modules with their degradation rates. The average degradation rate observed is around 2.05\%/year which is quite higher than the rates seen in European countries. However, it could be seen that there is a wide variance in the degradation rates. The modal value (most occurring degradation rate) is observed at $1.5 \%$ year and the median is $2 \% / y e a r$. Therefore, to understand the degradation rates distribution in a better way, the degradation rates are plotted separately based on the climate and the manufacturer. The $\mathrm{x}$-axis of the figure. (4b) represents the five different sites (A-E) along with the different manufacturers (1-6) with different colour codes. For instance, manufacturer ' 1 ' modules are found in two sites (A, D) and two climates zones (hot and dry, hot and humid) in this survey. One can observe that the degradation rates in hot and dry climate are much higher (about $>6 \%$ /year) along with high dispersion rates. In contrast, hot and humid climate shows fewer degradation rates with tight bound degradation rates except for site $\mathrm{A}$. The reason is due to extensive observation of encapsulate discolouration and front panel delamination

PV Technology also plays a crucial role in withstanding the outdoor robust environmental conditions. Our environment is surrounded by a lot of various disturbances such as dust, temperature and irradiance intensity. These variations vary widely from place to place in the world. The expected performance and reliability of PV technologies as specified by manufacturers in one region cannot be expected to perform the same level in the other parts of the globe. Therefore, it is necessary to separate and analyze the PV module performances with respect to technology as well. The characteristics and performance of PV technology differ in one climate with other climates. For instance, earlier research by Jordan et al. [24] has shown that thin-film PV technology modules perform well even under hightemperature conditions. The power degradation rates based on PV technology under the different climatic conditions is shown in the figure. 5. The degradation rates seen in hot and dry climate is higher than the counterpart. One can observe from the figure. 5 that the multi-crystalline technology has witnessed larger degradation rates than the mono-crystalline and followed by the other PV technologies. The main reason for degradation in crystalline technologies is due to reduction in short-circuit current $\left(\mathrm{I}_{\mathrm{sc}}\right)$ and opencircuit voltage $\left(\mathrm{V}_{\mathrm{oc}}\right)$.

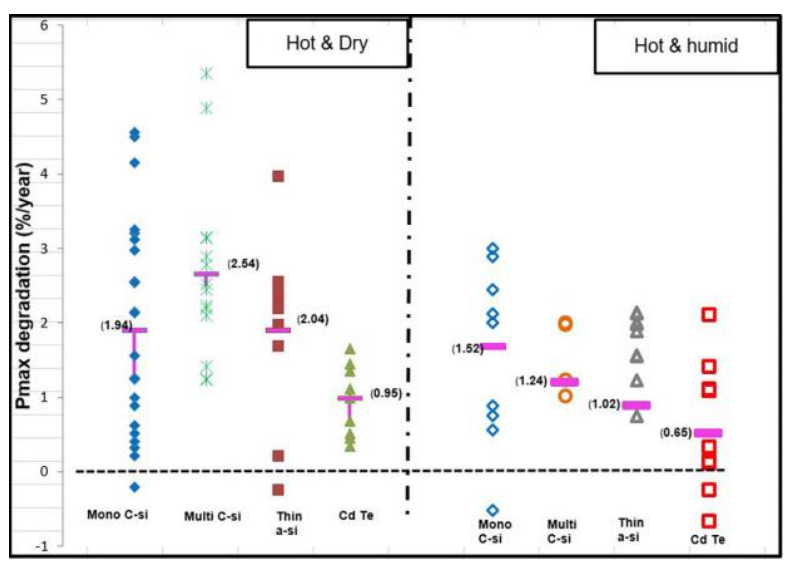

Figure 5. $\mathrm{P}_{\max }$ degradation rates based on climate and type of PV technology

A similar pattern is observed in Hot and humid climate, however, the overall degradation rates are lower than the rates observed in hot and dry climatic conditions. Surprisingly the degradation rates seen in Multi-crystalline silicon technology (1.24\%/year) is lower than monocrystalline technology. A definitive conclusion cannot be possible at this moment, as the number of inspected modules are less in this climatic zone. The thin film PV technologies have shown fewer degradation rates comparatively with the silicon technologies. Especially CdTe is observed with lowest degradation rates in both the climatic zones and seems to be the best PV technology according to the local environmental conditions. However, an extensive research study is still needed to find the appropriate PV technology for the local climatic conditions. The general degradation rates [25] observed for thin-amorphous silicon is less than $1 \% /$ year and CdTe is around $0.6 \% / y e a r$. These rates agree very well with the degradation rates observed in 
our survey. However, the silicon technology has shown higher degradation rates which raises concerns about its long-term performance in the local climatic zones. As a part of interest to understand how electrical parameters degradation rates differ by various PV technologies, an analysis is conducted where all crystalline modules (Mono and Multi) are in one group and thin film technologies in another group. The observed crystalline-silicon technology electrical parameters degradation rates are $\mathrm{P}_{\max }(2.11 \% /$ year $), \mathrm{I}_{\mathrm{sc}}$ (1.21\%/year), $\mathrm{V}_{\text {oc }}(0.08 \% /$ year) and $\mathrm{FF}(1.01 \% /$ year $)$. On the other hand, the degradation rates observed in the thin-film group are $\mathrm{P}_{\max }\left(1.78 \%\right.$ /year), $\mathrm{I}_{\mathrm{sc}}$ (0.98\%/year), $\mathrm{V}_{\mathrm{oc}}(0.18 \%$ /year) and $\mathrm{FF}(1.31 \% /$ year $)$. Therefore, for the crystalline-silicon modules, the degradation is mainly due to degradation in $\mathrm{I}_{\mathrm{sc}}$ followed by fill factor (FF). similarly, in thin film modules the degradation is mainly due to degradation in FF followed by $\mathrm{I}_{\mathrm{sc}}$. One can also observe that the $\mathrm{V}_{\mathrm{oc}}$ offering in $\mathrm{P}_{\max }$ degradation is very less.

To understand the effect of PV module size, we have classified the PV modules into two categories. The power ratings of each PV modules in our survey lies in the range of $50 \mathrm{~W}_{\mathrm{p}}$ to $220 \mathrm{~W}_{\mathrm{p}}$. The PV modules whose power rating is less than $120 \mathrm{~W}_{\mathrm{p}}$ are considered in group $\mathrm{A}$ and the rest in group $\mathrm{B}$. The average degradation rate of $\mathrm{P}_{\max }$ in group A PV module is calculated and observed to be at $1.82 \% / y e a r$. Similarly, the average degradation rate of $\mathrm{P}_{\max }$ in group $\mathrm{B}$ is observed to be at $2.57 \%$ /year. From the above values we can say that the PV modules whose rating capacity is higher (i.e. group B) has shown higher degradation rates than the ones whose power rating capacity is lower. The reason might be due to improper practices in installation as most of them are installing in outdoor conditions where the temperature and the irradiance level is varying very frequently from module to module.

Similarly, to understand the effect of PV system size and the type of installation on the $P_{\max }$ degradation rates, we again separated the surveyed sites into two categories. First is small/medium size (less than $120 \mathrm{KW}_{\mathrm{p}}$ ) and second is large size (greater than $120 \mathrm{KW}_{\mathrm{p}}$ ). The reason for choosing such benchmark is due to the equal data concentration on either side of the two considered categories. Figure. $6(a)$. shows the results of degradation rates due to system size. The middle pink bar indicates the average value of all considered modules in that category. Surprisingly, one can see that the larger system size has shown lower degradation rates than the smaller system size which is unexpected. This is likely due to best installation practices and care taken in large systems which may be lacking in smaller systems.

$0.81 \% / y e a r$ degradation value seen for larger system size is close to international norms. Furthermore, we have also separated the degradation rates based on the type of installation for both system sizes. The type of installation of PV modules can be categorized into two types first is roof based installation and second is ground based installation. One can observe from figure. 6(b) that all the large systems size has seen with ground base installation and has lower degradation rates. Whereas the smaller system size has observed with both roof and ground based installations. Even in the lower system size
$(<120 \mathrm{KW})$ the ground based installation has seen with lower degradation rates than the roof based installations.

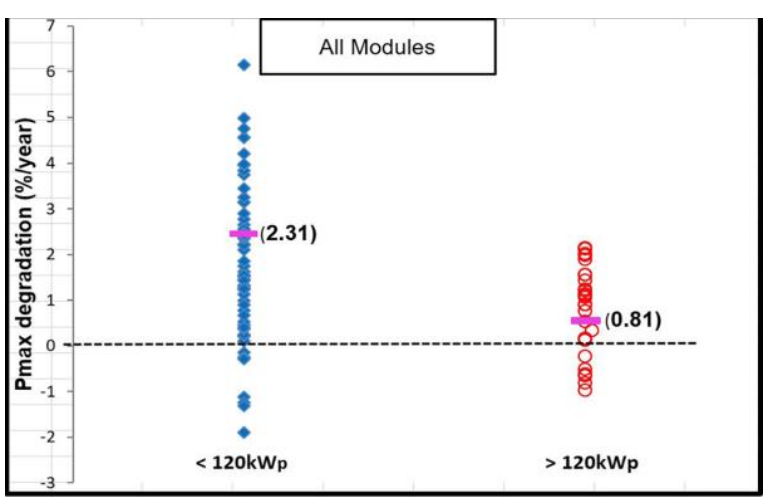

(a)

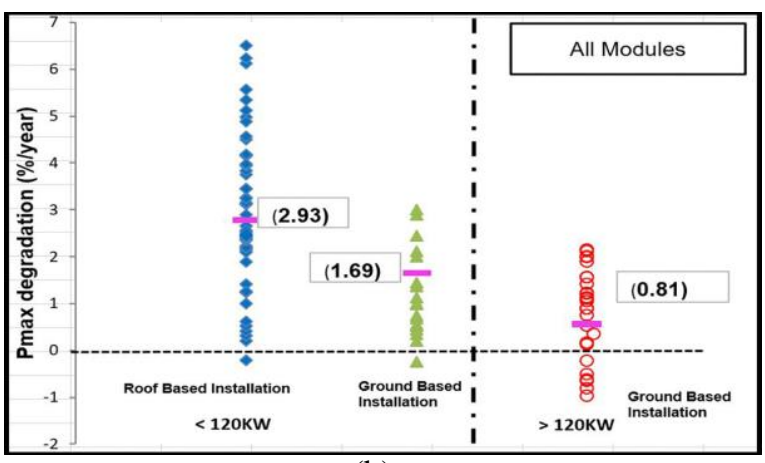

(b)

Figure 6. $\mathrm{P}_{\max }$ degradation rates

a) Effect of PV System size

b) Effect due to type of installation

The reasons for high degradation rates for roof based installations is likely due to hotter climatic which they witness directly than the ground based installations. This need special attention as 50MW of energy in future is going to be generated from roof tops as per MEDC (Muscat Electricity Distribution company).

\section{Conclusions}

Considering the Oman vision towards renewable energy it is vital to investigate the field performances of the photovoltaic modules so as to gain knowledge for the stakeholders, researchers etc. on ROI (return on investments) being made at present and in future. As a consequence, a case study has been performed on already installed PV modules on field under the local climatic conditions. The main visual degradations observed in field are encapsulate discoloration and front side delamination. Around $80 \%$ of the surveyed old age modules ( $\geq 5$ age group) has observed with encapsulate discoloration. The reason is due poor quality of encapsulate used during manufacture and also due to hot environment conditions. Therefore, for higher performance of PV 
modules for longer durations in the local climatic conditions the regular used encapsulate (EVA) seems to be an improper choice. Similarly, around $72 \%$ of the old age group PV modules has observed with delamination of the front-side panel. The middle age group has also observed (around 50\% of PV modules) with front side delamination and this is mainly due to snail trails formation at this age group. A part from visual degradations, other factors also effect the performance of PV modules such as its own optimum operation temperature. This increases due to cell cracks, hotspots formations etc. The effects of these are analyzed by considering the infra-red images (IR Images) taken on site. Further data analysis showed that the PV modules with 'hot cells' are showing higher degradation rates in both the climatic zones. Among the two zones the hot and dry zone PV modules has observed with a degradation rates of about $2.21 \%$ /year. This shows that the increase in optimum operating temperature of PV modules also become a significant factor in degradation rates of $\mathrm{PV}$ modules.

Proper function of interconnects in the PV modules is essential in delivery of generated current to the load. Any failure of interconnects in PV modules causes increase in series resistance there reducing the output power of PV modules. The surveyed data analysis showed that the SIB (severity of interconnects) is $27 \%(65)$ in hot and dry climatic zone while $14 \%(35)$ in the hot and humid zone. Comparatively, in both the zones the old age group modules has observed with higher SIB about $42 \%(35)$. This is mainly due to corrosion of bus bars which were dominantly observed in this age group. Average series resistance with SIB breakage interconnects has shown a good correlation. Similarly, a positive correlation is also observed with $\mathrm{P}_{\max }$ degradation rates vs SIB. The maximum degradation rate observed is $3.18 \% /$ year for SIB >41. The Electrical parameters analysis of PV modules also help us in understanding the performance of PV modules. All modules degradation rates of $\mathrm{P}_{\max }$ is observed about $2.05 \%$ /year which is quite higher than the European countries. Climate and manufacturer wise data analysis has showed that the PV modules installed in hot and dry climates has observed with high degradation rates than the counterpart. Further, the data has also separated based on the PV technology in both the climatic conditions. Multi-silicon crystalline PV technology has observed with highest degradation rates in both the zones. The reason is due to decrease in short-circuit current and temperature factors. The best possible PV technology in local climatic conditions seems to be CdTe whose degradation rates are less than $1 \% / y e a r$ and compares well with the international norms. However, a thorough research analysis is still required to arrive to a definitive conclusion regarding the best PV technology in the local climatic conditions. With regard to PV module size it has observed that small size $(<120 \mathrm{~W})$ has high average degradation rate about $1.82 \%$ year. On the contrast, with regard to PV system size the smaller systems size $(<120 \mathrm{KW})$ has lower average degradation rate about $2.31 \%$ /year. This is likely due to poor installation practices adopted by for small size installations. Furthermore, to gain an insight, based on type of installation the data has separated into roof based and ground based installations. The results showed that the roof based installations has seen higher average degradation rate about $2.93 \% / y e a r$ as they tend to run hotter than ground based installations. The results and conclusions which have become apparent in this survey may provide performance indicator factors for future deployment of PV systems in Oman.

\section{References}

[1] 'chronicles of the Middle East \& North Africa', Oman Geography; https://fanack.com/oman/geography/ (5 February 2018).

[2] 'National Centre for statistics information', Oman Population; https://www.ncsi.gov.om/Pages/NCSI.aspx (5 February 2018).

[3] 'OPWP's 7-Year Statement', Oman Power and Water procurement co.(SAOC);

http://www.omanpwp.com/PDF/7YS\%202016-

2022\%20Final\%20.pdf (5 February 2018).

[4] 'RenewableReadynessAssesment in Sultanate of Oman',IRENA;

http://www.irena.org/publications/2014/Nov/RenewablesReadiness-Assessment-Sultanate-of-Oman (5 February 2018).

[5] Sabah A. Abdul-Wahab et.al. ' $\mathrm{CO}_{2}$ greenhouse emissions in Oman Over the last forty-two years: Review', Elsevier Renewable and Sustainable Energy Reviews 52 (2015), pp. 1702-1712.

[6] Hussein A. Kazem 'Renewable energy in Oman: Status and future prospects', Elsevier Renewable and Sustainable Energy Reviews 15 (2011), pp. 3465-3469.

[7] Umar, T. and Wamuziri, S., 2016. Briefing: Conventional, wind and solar energy resources in Oman. Proceedings of the Institution of Civil Engineers-Energy, 169(4),pp.143-147. https://doi.org/10.1680/jener.16.00011.

[8] Umar, T., 2017. Geothermal energy resources in Oman. Proceedings of the Institution of Civil Engineers-Energy, 171(1), pp.37-43. https://doi.org/10.1680/jener.17.00001.

[9] Umar, T., 2017, July. Towards a sustainable energy: the potential of biomass for electricity generation in Oman. In Proceedings of the Institution of Civil EngineersEngineering Sustainability (pp. 1-5). Thomas Telford Ltd. https://doi.org/10.1680/jensu.17.00001.

[10] Umar, T. and Egbu, C., 2018, June. Global Commitment Towards Sustainable Energy. In Proceedings 
of the Institution of Civil Engineers-Engineering Sustainability (pp. 1-38). Thomas Telford Ltd. https://doi.org/10.1680/jensu.17.00059.

[11] Umar, T., 2017. Rooftop solar photovoltaic energy: a case study of India. Nanomaterials and Energy, 6(1), pp.1722. https://doi.org/10.1680/jnaen.16.00002

[12] 'Muscat Electricity Distribution Company', MEDC Solar PV systems; https://www.medcoman.com/solarenergy.php (6 February 2018).

[13] Hussein A. Kazem 'Feasibility of Photovoltaic Systems in Oman', IEEE-Smart Grid and Renewable Energy Workshop (2015), DOI. 10.1109/SGRE.2015.7208721.

[14] Neelesh Umachandran et.al. 'Statistical methods to determine dominant degradation modes of fielded PV modules', IEEE-42 ${ }^{\text {nd }}$ PVSC conference (2015), DOI: 10.1109/PVSC.2015.7355699.

[15] Joseph M. Kuitche et.al 'Investigation of Dominant Failure Mode(s) for Field-Aged Crystalline Silicon PV Modules Under Desert Climatic Conditions', IEEE-Journal of Photovoltaics (2014), pp. 814-826.

[16] D. C. Jordan et al. , 'PV degradation curves: non linearities and failure modes', Progress in Photovoltaics: Research and Applications (2017), vol. 25, pp. 583-591.

[17]'Light induced Degradation (LID)',PVSyst; http://files.pvsyst.com/help/lid_loss.htm (6 February 2018).

[18]B.Sopori,et al., "Understanding Light-Induced Degradation of c-Si Solar Cells", 38th IEEE Photovoltaic Specialists Conference, Austin, (2012). DOI: 10.1109/PVSC.2012.6317798

[19] C.E. Packard et al., 'Development of a visual inspection data collection tool for evaluation of fielded PV moduled condition', (2012), NREL Report No. NREL/TP-520056154.

[20] Tamizhmani et al., 'Failure and Degradation Modes of PV Modules in a Hot Dry Climate: Results after 12 to 26 years of field exposure',(2013), NREL PV Module Reliability Workshop.

[21] R. Moreton et al., 'Dealing in Practice with Hot Spots' (2014), 29th European Photovoltaic Solar Energy Conference and Exhibition, Amsterdam, pp. 2722-2727.

[22] J. Oh and G. TamizhMani, 'Temperature Testing and Analysis of PV modules per ANSI/UL 1703 and IEC 61730 standards', (2010), 35th IEEE Photovoltaic Specialist Conference, Honolulu, pp. 984-988.

[23] Mohamed s. honnurvali et al, 'PV Electrical Parameters Degradation Analysis-Oman Perspective', (2017), $8^{\text {th }}$ IEEEIREC conference, DOI:10.1109/IREC.2017.7926000.

[24] Jordan et. al., 'Compendium of photovoltaic degradation rates, (2016), prog. In photovoltaics Res. Appl.24: pp. 978-989.
[25] Jordan et. Al., 'photovoltaic degradation rates-an analytical review', (2013), Prog. In photovoltaics Res. Aool.,21: pp.12-29. 